\title{
Resistance to treatment and change in anorexia nervosa: a clinical overview
}

\author{
Giovanni Abbate-Daga, Federico Amianto, Nadia Delsedime, Carlotta De-Bacco and Secondo Fassino*
}

\begin{abstract}
Background: Current literature on Eating Disorders (EDs) is devoid of evidence-based findings providing support to effective treatments, mostly for anorexia nervosa (AN). This lack of successful guidelines may play a role in making these disorders even more resistant. In fact, many individuals do not respond to the available treatments and develop an enduring and disabling illness. With this overview we aimed to highlight and discuss treatment resistance in AN - with an in-depth investigation of resistance-related psychological factors.

A literature search was conducted on PubMed and PsychINFO; English-language articles published between 1990 and 2013 investigating the phenomenon of resistance to treatment in AN have been considered.
\end{abstract}

Discussion: The selected papers have been then grouped into four main thematic areas: denial of illness; motivation to change; maintaining factors and treatment outcome; and therapeutic relationship. Eating symptomatology was found to only partially explain resistance to treatment. The role of duration of illness has been questioned whilst some maintaining factors seemed promising in providing a useful framework for this phenomenon. Emotive and relational aspects have been investigated on their role in resistance as well as therapists' countertransference.

Summary: Remarkably there has been little research done on resistance to treatment in the ED field, in spite of its clinical relevance. Motivation, insight and subjective meaning of the illness can be useful tools to manage the resistance phenomenon when coupled with a wider approach. The latter enables the therapists to be aware of their role in the therapeutic alliance through countertransference aspects and to consider the EDs as disorders of the development of both personality and self, entailing severe impairments as regards identity and relationships.

Keywords: Anorexia nervosa, Eating disorders, Psychodynamic psychotherapy, Resistance, Change, Insight, Therapeutic relationship, Maintaining factors, Defense mechanisms, Countertransference

\section{Background}

Resistance to treatment has been variously interpreted across psychiatric disorders with this concept being often used as a synonym of difficult-to-treat disorders. In literature, there is a general consensus that the available treatments for major psychiatric disorders frequently result in either a lack of effect or a moderate response. Accordingly, to challenge treatment-resistance is fundamental in psychiatric clinical practice and it also represents a crucial public health problem [1].

Two issues should be carefully addressed while studying the phenomenon of treatment resistance. First, patients' apparent strong wish for treatment often not

\footnotetext{
* Correspondence: secondo.fassino@unito.it

Eating Disorders Center for Treatment and Research, Department of Neuroscience, University of Turin, Turin, Italy
}

resulting in any improvement, and second, the profound resistance - with conscious and unconscious aspects related to the distress triggered by changing [2] which is a hallmark of Eating Disorders (EDs).

EDs are serious and complex mental illnesses [3] with a biopsychosocial pathogenesis [4] and that are often characterized by a chronic and disabling course [5]. Recent follow-up studies failed to provide evidence that treatments can influence long-term results [6] with relevant consequences on public health-related costs [7-9]. The only exception is represented by adolescents affected by anorexia nervosa (AN) reporting a more favorable outcome when compared to adults [10]. In fact, one-third of adult AN patients show poor outcome also because of an enduring and refractory illness [5,11]
C Bïomed Central

(c) 2013 Abbate-Daga et al.; licensee BioMed Central Ltd. This is an open access article distributed under the terms of the Creative Commons Attribution License (http://creativecommons.org/licenses/by/2.0), which permits unrestricted use, distribution, and reproduction in any medium, provided the original work is properly cited. 
whilst many maintaining factors of the AN symptomatology are less entrenched in younger patients [10].

In AN, both avoidance of treatment [12] and dropouts - ranging between 20 and $51 \%$ in the inpatient population and from 23 to $73 \%$ in outpatient samples - are related to the great difficulty existing in engaging and maintaining their treatment adherence [13,14].

In $\mathrm{AN}$, willingness to improve represents only one of several factors required to achieve recovery. In fact, reluctance to recover is sustained by ego-syntonic symptoms that reinforce the illness [15-17] and relapse is common $[18,19]$ also because patients often perceive consequences of AN as positive and adaptive [20]. Symptoms and pathologic beliefs are indeed intertwined in $\mathrm{AN}$, revealing a self-protecting meaning. Eating psychopathology is underpinned by several entangled biopsychosocial elements personality, general psychopathology, environment, and treatment itself - that may have a role in both increasing and lowering patients' willingness to recover.

For many years, the possible meanings of eating symptomatology have been debated; studies investigating patients' perspectives have finally demonstrated how patients often describe AN as a means of obtaining identity, avoiding negative emotions, and satisfying a strong need for control [21]. Patients are reluctant and ambivalent about changing and they can unconsciously oppose a strong resistance to their therapists' efforts towards improvement. Defense mechanisms that protect patients by negative feelings are often directly activated by therapy paving the way to resistance [2]. The peculiar defense mechanisms in AN - denial and intellectualization - can become resistance to treatment when patients are asked to face both changes and negative affect [22,23]. AN should be considered indeed not only as a constellation of physical and psychological symptoms but also as an array of self-protecting behaviors able to give patients respite from distress [24].

Although these aspects are well-known to clinicians, there is a dearth of organized and critical studies in the AN field on resistance to treatment and motivational therapies.

The aim of the present paper is to gather and discuss the studies published from 1990 to 2013 on the topic of treatment resistance in AN since a better understanding of poor motivation to treatment is fundamental to provide more tailored therapies. The research questions underpinning this article arose from the need of a deeper understanding of 4 core areas with regard to AN treatment: namely, we considered the role of: 1 . illness awareness; 2. patients' willingness; 3 . psychopathological factors ED symptomatology-related; 4. therapist.

\section{Methods}

Article search has been conducted using PubMed and PsychINFO databases using the following MeSH terms: "anorexia nervosa", "bulimia nervosa", "eating disorders", "motivational change", "insight", "predictors of outcome", "treatment resistance", "decision making", "psychosis", "countertransference". The first three terms have been alternately used as fixed research criteria. This MeSH search yielded 142 articles pertaining to treatment resistance in EDs.

Abstracts or full texts have been then gathered and selected by two different researchers (ND and AF) to check the following inclusion criteria: a) AN diagnosis; b) original research or debate articles, c) being published after 1990, and d) English language. Exclusion criteria were: a) samples diagnosed with unstandardized instruments or according to unspecified criteria; b) case reports; c) letters; and d) editorials.

We decided to include not only original research but also debate articles for two major reasons. First, to date the relationship with patients has been scarcely investigated, mostly by qualitative studies and debate-framed articles. Second, currently there is such a dearth of evidence-based data in the treatment of $\mathrm{AN}$ that the opinion of highly experienced researchers and clinicians is extremely valuable.

According to the aforementioned criteria we finally selected 71 articles to be included in this overview whilst 71 have been excluded because not meeting the inclusion criteria.

We could not perform a meta-analysis because of the differences we found among studies regarding sample composition, methodology used in the assessment of patients, and different outcome criteria. To achieve greater clarity, the gathered articles have been divided into four thematic areas grounded on the 4 aforementioned research questions (1. role of illness awareness; 2. role of patients' willingness; 3. role of psychopathological factors ED symptomatology-related; 4 . therapist's role): denial versus insight of illness; motivation to change; maintaining factors and treatment outcome; therapeutic relationship, countertransference, management of treatment resistance (see Table 1). Studies encompassing more than one area have been distributed under more sections.

\section{Results}

\section{Sample composition}

We included in this overview 71 studies with a variable sample composition ranging from 14 to 748 participants. No reviews or meta-analysis on this topic were available. Three of the considered studies recruited clinicians instead of patients $[85,87,90]$ to investigate their countertransference. As regards the study design, we found debate articles, randomized controlled trial (RCT), qualitative interview, test validations, longitudinal cohort, cross-sectional, prospective cohort, and retrospective cohort studies (see Table 1). 
Table 1 Articles included in the clinical overview; they have been divided into 4 thematic areas based on 4 research questions: 1 . role of illness awareness; 2. role of patients' willingness; 3. role of psychopathological factors 4 . therapist's role

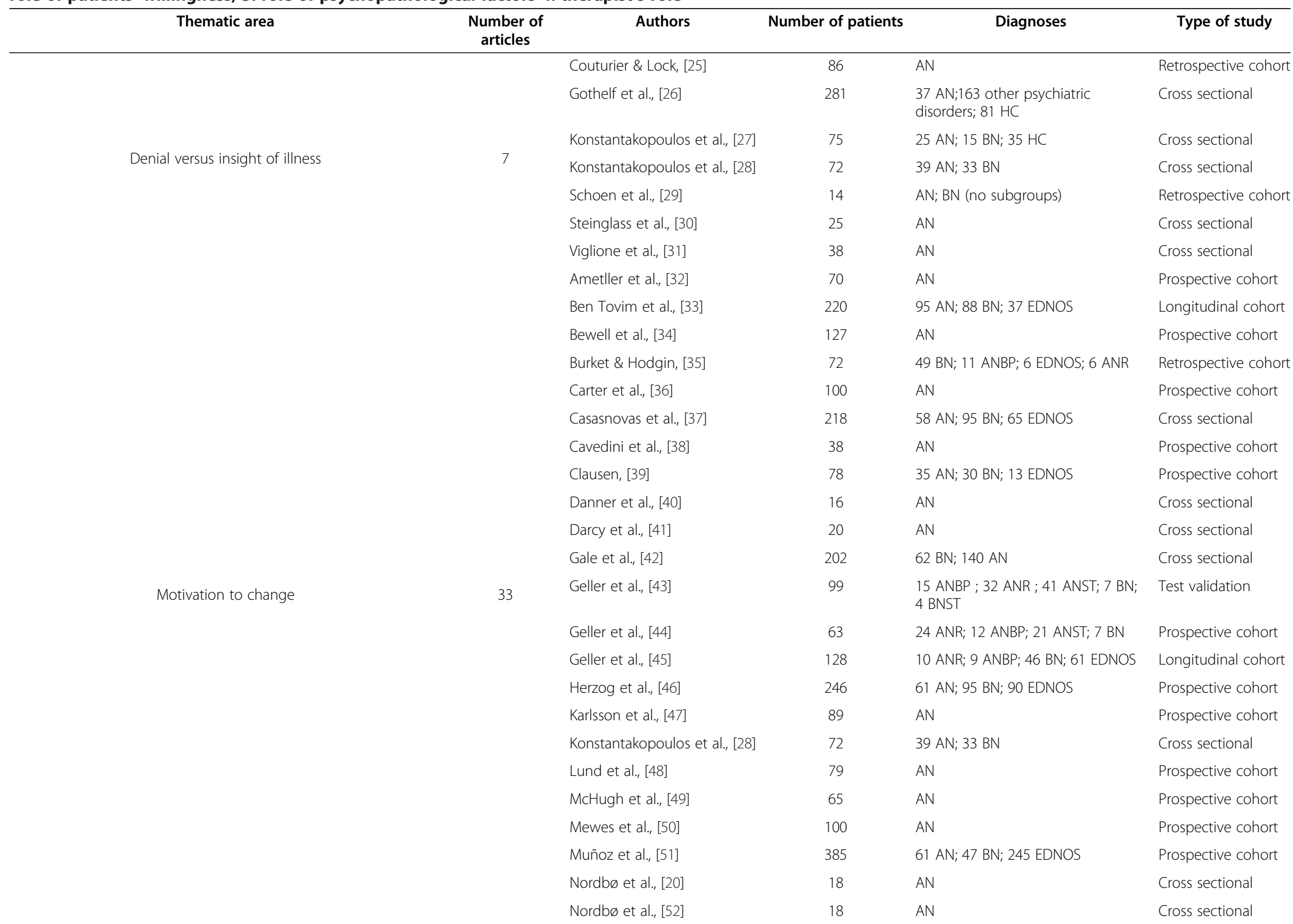


Table 1 Articles included in the clinical overview; they have been divided into 4 thematic areas based on 4 research questions: 1 . role of illness awareness; 2. role of patients' willingness; 3. role of psychopathological factors 4 . therapist's role (Continued)

Nordbø et al., [53]
Ricca et al., [54]
Rieger et al., [55]
Salbach-Andrae et al., [56]
Schebendach et al., [57]
Steinglass et al., [30]
Touyz et al., [58]
Treasure et al., [59]
Wade et al., [60]
Ward et al., [61]
Castro et al., [62]
Clausen, [39]
Danielsen \& Rø, [63]
Deter et al., [64]
Fairburn et al., [65]
Fassino et al., [66]
Fassino et al., [67]
Fassino et al., [68]
Federici \& Kaplan, [69]
Fichter et al., [18]
Geller et al., [70]
Goddard et al., [71]
Helverskov et al., [72]
Hjern et al., [73]
Löwe et al., [74]
Salbach-Andrae et al., [56]
Schmidt \& Treasure, [75]
Signorini et al., [76]
Steinhausen et al., [77]
Tussell., [10]
Thnock et al., [78]
The

53 AN: 50 ANST

AN

AN

AN recovered

AN

AN

22 ANR; 11 ANBP; 2 BN

AN

35 AN; 30 BN; 13 EDNOS

$30 \mathrm{AN} ; 9$ BN; 11 EDNOS

AN

AN

AN

$28 \mathrm{AN} ; 29 \mathrm{BN}$

AN

AN

\section{$63 \mathrm{AN} ; 7$ BN; 4 EDNOS}

58 AN; 68 EDNOS-AN; 111 BN; 75 EDNOS-BN

AN

AN

AN

AN

48 ANR; 6 ANBP; 5 Atypical AN; 1

BN

AN
Cross sectional

Prospective cohort

Test validation

Prospective cohor

Prospective cohor

Cross sectional

Debate article

Debate article

Prospective cohort

Cross sectional

Prospective cohor

Prospective cohort

Prospective cohort

Prospective cohort

Debate article

Prospective cohort

Prospective cohort

Prospective cohort

Cross sectional

Prospective cohort

Debate article

Prospective cohort

Prospective cohort

Prospective cohort

Prospective cohort

Prospective cohort

Debate article

Prospective cohort

Prospective cohort

Prospective cohort

Debate article 
Table 1 Articles included in the clinical overview; they have been divided into 4 thematic areas based on 4 research questions: 1 . role of illness awareness; 2. role of patients' willingness; 3 . role of psychopathological factors 4 . therapist's role (Continued)

\begin{tabular}{|c|c|c|c|c|c|}
\hline & & Vrabel et al., [79] & 74 & $13 \mathrm{AN} ; 37 \mathrm{BN} ; 24$ EDNOS & Prospective cohort \\
\hline & & Carter et al., [36] & 100 & AN & Prospective cohort \\
\hline & & Darcy et al., [41] & 20 & AN & Cross sectional \\
\hline & & Federici \& Kaplan, [69] & 15 & AN & Cross sectional \\
\hline & & Feld et al., [80] & 19 & 8ANR; 4ANBP; 4 BN; 3 EDNOS & Prospective cohort \\
\hline & & Forget et al., [81] & & & Debate article \\
\hline & & Geller et al., [82] & 181 & $\begin{array}{l}\text { Cases: } 3 \text { ANBP; } 4 \text { ANR; } 22 \text { BN; } 28 \\
\text { EDNOS }\end{array}$ & $\mathrm{RCT}$ \\
\hline & & & & $\begin{array}{l}\text { Controls:3 ANBP; } 4 \text { ANR; } 21 \text { BN; } 28 \\
\text { EDNOS }\end{array}$ & \\
\hline & & Gulliksen et al., [53] & 38 & AN & Cross sectional \\
\hline \multirow{11}{*}{$\begin{array}{c}\text { Therapeutic relationship, countertransference, management of } \\
\text { treatment resistance }\end{array}$} & \multirow{11}{*}{18} & Karlsson et al., [47] & 89 & AN & Prospective cohort \\
\hline & & Masson \& Sheeshka, [83] & & & Qualitative interview \\
\hline & & Moyers \& Rollnick, [84] & & & Debate article \\
\hline & & Satir et al., [85] & $120(\mathrm{HP})$ & & Cross sectional \\
\hline & & Skårderud et al., [24] & & & Debate article \\
\hline & & Strober et al., [86] & & & Debate article \\
\hline & & Tierney \& Fox, [87] & $53(\mathrm{HP})$ & & Cross sectional \\
\hline & & Tozzi et al., [88] & 70 & AN & Cross sectional \\
\hline & & Treasure et al., [59] & & & Debate article \\
\hline & & Vitousek et al., [89] & & & Debate article \\
\hline & & Warren et al., [90] & $43(\mathrm{HP})$ & & Cross sectional \\
\hline
\end{tabular}

AN Anorexia Nervosa, BN Bulimia Nervosa, ANR Anorexia Nervosa Restricting subtype, ANBP Anorexia Nervosa Binge-Purging subtype, EDNOS Eating Disorder Not Otherwise Specified, ANST Subthreshold Anorexia Nervosa, BNST Subthreshold Bulimia Nervosa, EDNOS-AN anorexia-like eating disorder not otherwise specified-anorexia nervosa, EDNOS-BN anorexia-like eating disorder not otherwise specified-bulimia nervosa, $H C$ Healthy Controls, HP healthcare practitioners, RCT randomized controlled trial. 


\section{Diagnosis}

As regards ED diagnosis, according to Diagnostic and Statistical Manual criteria (DSM-IV-TR) [91], 32 studies included only AN individuals, in one case recovered$\mathrm{AN} ; 9$ papers considered bulimia nervosa (BN) and $\mathrm{AN}$ individuals, in one case compared to healthy controls (HC); 14 studies $\mathrm{AN}, \mathrm{BN}$ and eating disorder not otherwise specified (EDNOS) participants. A study compared AN patients with subthreshold-AN individuals. In another work have been included patients with other psychiatric diagnoses and $\mathrm{HC}$. The remaining studies were debate articles or did not consider affected individuals.

\section{Thematic areas}

\section{Denial versus insight of illness (7 studies)}

Konstantakopoulos and Coworkers [27] highlighted how the restricting AN subtype is strongly characterized by lack of insight of illness and how the latter correlates with cognitive flexibility as measured with the trail making test. A couple of studies included in this area underscored that poor insight can assume delusional features, defining then a specific subgroup of AN patients even more treatment-resistant $[28,30]$.

Moreover, two studies highlighted how insight of illness can be a helpful element in overcoming scarce compliance with therapy. Schoen and Coworkers [29] in a recent paper demonstrated a correlation between insight of illness and the seeking of professional treatments whilst other authors [31] supported indeed that duration of illness correlates with greater insight rather than with a more severe disorder.

Other three studies toned down the role of insight in overcoming poor compliance to treatments: it could be not only the lack of insight to maintain the disorder but also the combination of mature and immature defense mechanisms [26]. In fact, the majority of treatmentresistant patients show a clear denial of illness rather than scarce insight [27]. Moreover, it has been recently shown by the same authors - not in line with previous studies [31] - that insight is not related to duration of illness and that poor insight can be maintained also in a chronic phase of the ED [27]. Finally, Couturier and Lock [25] demonstrated how denial of illness does not impact significantly the outcome of family therapy.

\section{Motivation to change (33 studies)}

A few studies evaluated psychological determinants of motivation to change and only one paper investigated the correlation between motivation to change and quality of life as perceived by patients [51] but - given its cross-sectional design - it is not clear whether motivation can be influenced by quality of life or vice versa.

As regards cognitive factors, only one paper [38] found neurocognitive traits, in particular decision making impairment, as possibly involved in determining a less favorable outcome after Cognitive Behavioral Therapy (CBT), as well as lower weight gain and poorer motivation to change. AN patients would be cognitively oriented to choose short-term rather than long-term rewards with these features entailing poorer compliance to treatments and a less positive outcome. Recently, Danner and Coworkers [40] highlighted a significant correlation between set-shifting and central coherence raising the hypothesis of a relevant link - as regards prognosis - between these traits and treatment outcome. However, the authors underscored also that such deficits are shared by both ill and recovered-AN individuals so they cannot be predictors of motivation to change.

Eleven studies included in this thematic area investigated quality and content of motivation. Three studies conducted by Nordbø and Coworkers demonstrated that a treatment independent willingness to recover is a fundamental requirement to readiness to change $[17,20,52]$ and another work showed that patients' willingness to change, as expressed at the beginning of treatment, is a relevant prognostic factor at six-month follow-up [47]. In line with these findings, an improved motivation to change during therapy represents a crucial factor in overcoming relapses [36]. All these studies highlight how patients' attitudes towards illness should be accounted for while defining motivation to change [20] and investigated at the beginning of treatment [51].

It is noteworthy that those motivations verbally expressed by patients often do not correspond to an authentic intention to modify their eating disordered behaviors since ED patients can be strongly ambivalent about changing [52]. The ambivalence issue has been confirmed also by another study [42] suggesting the use of the Pros and Cons of Eating Disorders Scale as useful tool to evaluate patients' perspective of illness. Moreover, a longer duration of illness - index of poor motivation to change - is a negative prognostic factor mostly in AN [39].

Another paper investigated preoccupation with weight and body and found it to be determinant as regards CBT outcome and the chance to overcome treatment resistance [54]. The intensity of such a preoccupation can assume a delusional connotation with repercussions on resistance to treatment by lowering motivation [28] and generating strong ambivalence [30].

Twelve studies highlighted the correlation between patients' clinical features and their motivation to change. In fact, BN patients are usually more motivated to seek treatment and change than both AN and subthreshold-AN individuals, mostly if chronic [37], and there is general consensus that binge-purging $\mathrm{AN}$ individuals show an unfavorable outcome [56]. Another recent study suggested indeed a more positive prognosis for EDNOS individuals; 
they seemed to achieve a more rapid and stable remission and showed indexes of higher motivation when compared to individuals affected by a full diagnosis [39], providing further support to data already known in literature $[33,46]$. Those patients with normal body mass index (BMI), showed a more rapid improvement in motivation to change than those with a low BMI [45] and, more in general, baseline BMI was the most significant predictor of outcome in the whole ED diagnostic group [39]. Moreover, poor motivation to change correlated also with laxatives abuse, depression, and body dissatisfaction [35], although some researchers [35] could not find a correlation between clinical severity and poor motivation to treatment, even if more recent studies did not confirm this hypothesis [45]. However, two studies [48,50] indicated that the rapidity of weight restoration is the only significant prognostic factor over the short and mediumterm with Lund and Coworkers [48] highlighting indeed how this can indirectly point out an enhanced motivation to treatment. Finally, Schedenbach and Colleagues [57] underscored that the best predictors of treatment outcome are the ability to choose a variety of foods, mostly with high caloric density.

Eleven studies highlighted how motivation to change can quantitatively vary and several papers on AN described different stages of change and their influence on both outcome and resistance. Some authors demonstrated that the extent of clinical improvements can vary also depending on the stage of motivation achieved by patients [61] and that a mismatch between stage of motivation and phase of treatment can enhance resistance to treatment [58]. Other studies correlated motivation-to-change levels to the need and duration of hospitalizations, finding that high motivation correlates with short duration of inpatient treatment and better outcome [49]. Conversely, if the motivation level is low - i.e. pre-contemplation phase according to Prochaska's model [92] - the need for hospitalizations resulted to be higher [32].

Motivation to change can be improved by sharing treatment plans with patients [41] and can be assessed with the Motivational Interview [93], the Readiness and Motivation Interview [43,44], or the Anorexia Nervosa Stages of Change Questionnaire [55]. Some studies showed that the latter is a useful instrument to predict changes in eating symptomatology [60] and outcome since motivation plays a mediator role between them [34].

\section{Maintaining factors and treatment outcome (22 studies)}

Although early studies discouraged the search for EDspecific maintaining factors highlighting instead the need of long-term treatments [77], some recent papers called into question the need for their identification and reformulation [70].
Fairburn [65] designed a transdiagnostic cognitivebehavioral therapy for EDs, aiming at addressing maintaining factors; he individuated as main element a scheme of dysfunctional self-evaluation by which patients attribute exaggerated relevance to eating, body shape, and weight. He considered both ED-specific factors (i.e. thoughts about eating, weight, body shape, hyperactivity) and non ED-specific factors like low self-esteem, interpersonal problems, emotional intolerance, and perfectionism. The latter interact with both individual's specific psychology and other maintaining factors [65].

Perfectionism has been considered also by other authors [78], demonstrating that some of its aspects could represent a transitional status associated to pathology and are no longer present in recovered AN individuals.

In addition, more authors individuated in body image an outcome predictor of hospitalization even more reliable than interpersonal problems and general psychopathology pointing out indeed how body perception instead of body dissatisfaction can be an indicator of treatment progression [63].

Other psychopathological factors with prognostic value were: inadequacy, high asceticism and maturity fear, impulsivity, and sexual problems [18,66-68]. As regards intra-psychic elements instead, one study individuated as ED maintaining factors poor problem solving and relational skills [69].

Five studies considered personality traits as ED maintaining factors. Fassino and Coworkers [66-68] pointed out how low novelty-seeking and high harm-avoidance - along with other psychopathological aspects - represent predictors of poor outcome in an ED multimodal treatment.

Other studies [76] demonstrated instead that narcissistic personality traits were related to strong resistance to weight gain in treated AN individuals and that depressive and psychotic traits entailed better or poorer prognosis, respectively. Another paper [73] with a 9 and 14-year follow-up found that Axis I and II psychopathology could predict both poor outcome and numerous hospitalizations in the ED population. A couple of studies $[56,64]$ confirmed the negative role of general psychopathology on AN prognosis at the 12-year follow-up, whilst another paper [39] found it significant mostly about BN.

Further authors [79] underscored indeed how avoidant personality traits, coupled with a history of sexual abuse, can play a negative role on long-term prognosis after hospitalization. Assuming a categorical approach to study personality, Helverskov and Coworkers [72] acknowledged the presence of a personality disorder as a negative prognostic factor shared by all EDs.

Castro and Colleagues [62] investigated the prognostic meaning of parental bonding on the outcome of shortterm therapy in AN. Even highlighting how parental bonding was not particularly different from healthy 
controls, the authors underscored that parental hyper control as well as having a rejecting father entail are both elements that strongly impact treatments, in addition to ED psychopathology. Recently, some authors [71] supported the role of caregivers' expressed emotions and reinforcing behaviors as interpersonal maintaining factors. In their work it has been indicated that reducing caregivers' distress leads to improving patients' functioning and eating pathology.

Schmidt and Treasure [75] considered as maintaining factors both intrapersonal and interpersonal factors, placing only scarce emphasis on biological elements and body weight. Also Treasure and Coworkers [94] analyzed the interpersonal maintaining factors of EDs pointing out that over protection, coercive treatments, and isolation could be iatrogenic factors.

Finally, two papers investigated psychosocial factors as the lack of a partner, poor family support, and unemployment as relevant predictors of poor outcome at 21 [74] and 12-year follow-up [64]. Another study [39] showed how the scarcity of friends is a negative prognostic factor in EDNOS patients.

\section{Therapeutic relationship, countertransference and management of treatment resistance (18 studies)}

The studies considered in this thematic area - deepening poor compliance and scarce motivation to treatments - indirectly suggested different models to treat resistant patients.

Carter and Colleagues [36] highlighted how improving and maintaining motivation to treatment during therapy can show a relevant impact on the long-run. Accordingly, it has been shown the need to specifically address motivation as much as social relationships and body image with tailored interventions to obtain an adequate weight restoration, even with acute AN patients [47].

A couple of studies illustrated rehabilitation - with a focus on psychosocial interventions [87] or supportive therapy [86] - constantly advocating the need for tailoredto-person treatments.

Five studies suggested interventions focused more directly on overcoming poor compliance to treatments with an approach aiming at improving motivation to change and treatment. Already Vitousek and Colleagues years ago [89] underscored the importance of improving motivation to change. With their paper, they suggested some cognitive-behavioral strategies that can be applied also to other theoretical models to enhance emotively and cognitively the therapeutic alliance to overcome resistance. In fact, the authors highly recommend to emotionally validate patients by accepting their difficulties and by speaking their language, adopting a Socratic style in the exploration of both ambivalence and resistance to treatment.
Another effective intervention was the Motivational Interview, an approach based on the Socratic method, emphasizing patients' autonomy and discouraging direct persuasion [84]. Geller and Coworkers [82] demonstrated the effectiveness of Readiness and Motivation Therapy to lower ambivalence and improve change; also Motivational Enhanced Therapy was found to be effective to achieve this goal, even if in a less structured way [80].

A theoretical paper [83] highlighted that clinical interventions should sometimes indulge patients' resistances; the discharge of poorly motivated patients can be necessary to maintain a therapeutic milieu focused on recovery and to avoid poor compliance $[83,89]$.

Finally, other studies suggested interventions to overcome scarce compliance not directly focusing on patients but rather on therapists, highlighting the need to handle correctly their countertransference since it could play a negative role on treatment $[59,85]$. Countertransference can be determined by both patients' [95] and therapists' features $[53,90]$ and supervision of therapist's emotions is highly recommended [81].

Patients highly value psychotherapy and therapeutic relationship considering them as useful elements in treatment $[69,88]$. Accordingly, it has been suggested to work with a particular focus on the patient-therapist interaction and on shared choices [41]. Concluding, a comment article proposed indeed to address the impairment in mentalization skills of ED patients within the therapeutic relationship [24].

\section{Discussion}

The aim of the present paper was to provide a clinical overview of the available literature on resistance to treatments in AN. It is indeed a well-known phenomenon theorized decades ago $[89,96,97]$ that represents a heavy burden for all clinicians [98]. We propose here a scientifically informed discussion since a systematic review of the literature has been hampered by a huge variety of methodologies used in the available studies leading to a lack of comparable data. Therefore, a systematic review of the literature to date would lead only to scarcely powered findings. As a further limitation, it should be born in mind that the biopsychosocial pathogenesis of AN would require to study several sources of knowledge. We will focus on psychosocial factors and emotive and relational impairments, omitting the biological aspects like the effects of starvation on brain functions.

But why is there a dearth of studies on resistance? This apparent disinterest seems to be due to several reasons. Firstly, it is likely that many authors conceive resistance to treatment as a whole with the illness. According to this perspective, the investigation of treatment outcomes in AN would correspond to evaluating resistance too 
[99]. Secondly, resistance to treatment is a widespread phenomenon. Hence, some of the papers we included in this overview $[14,54,100]$ pointed out how treatmentresistance in the AN field can be easy to notice but difficult to understand. In fact, it is a complex phenomenon that involves vulnerability and maintaining aspects with intertwined biological, psychopathological, and social features [101] that cannot be easily disentangled. Thirdly, in the last years, research focused more on resistance-related biologic aspects [102] rather than on clinical and relational ones [98]. Also psychodynamic psychotherapies have been even less studied although the assessment of resistance represents the core of the psychoanalytic method [103] since resistance can be enhanced by the relationship between patient and therapist. Finally, we could call into question clinicians' poor motivation to study their frustrated therapeutic attempts [94]. Whatever the reason, it may be a mistake not to carefully consider this phenomenon since it is a hallmark of psychiatry [104]. More in detail, since psychotherapy is an effective therapeutic instrument in the ED field, a better understanding of both resistance and strategies to address it should be carefully considered in treatments [2]. From the research questions underpinning this article we sorted our results into four core areas with regard to AN treatment.

\section{Denial versus insight of illness}

This is the most immediate and straightforward correlate of resistance to treatments in $\mathrm{AN}$ and it was included even in DSM-IV-TR diagnostic criteria [91]. Denial of illness is defined as the refusal to acknowledge and accept one's own illness and it refers not only to psychodynamic therapy and defense mechanisms [2] but also to a wider definition of disadaptive coping [105]. Denial of illness is an intrinsic factor of the first phases of AN [91] and it can last years [86], given the ego-syntonic nature of the anorectic disorder [106]. Accordingly, the Academy of EDs has clearly stated that EDs are severe mental illnesses that require a wide and multifaceted health care alert as like as other major psychiatric pathologies including bipolar disorder, schizophrenia, obsessive-compulsive disorder or depression [3].

We included 7 studies converging on the fact that a large number of AN patients deny their disorder [25-31]. This phenomenon can be particularly clear for those patients who need acute hospitalizations: a recent study conducted on a sample of 108 AN inpatients showed that the vast majority of them (63\%) deny their illness [107] with $20-30 \%$ of cases revealing a symptomrelated psychotic status $[28,30]$. These features may be so widespread because many patients tend to carry out a deliberate denial [27] or minimization [25] of their illness trying to justify - with different degrees of awareness - treatment refusal. In this regard, the data in literature are debated and do not clarify whether denial of illness is a psychosis-like symptom or rather a rigid and disadaptive defense mechanism helping patients to protect themselves by anxiety and depression $[26,31]$ and to avoid treatments [89] or negative emotions [22,23]. It is likely that both these aspects are true; nevertheless, hypothesizing denial as a defense mechanism could be more in line with its time consistency [86], independently of fluctuations in ED symptomatology [28,29].

Data are also controversial about the extent to what denial can impact prognosis since this element seems to be scarcely relevant as regards adolescents [25]. One paper highlighted a linear correlation between insight and duration of illness [31], although this finding has not been replicated [28]. At now, it is not possible to distinguish whether denial is already expressed at the onset of illness or it is enhanced with time and potentially by inappropriate treatments. However, it should be considered as a central issue to be addressed in treatments rather than a prognostic element [29].

The improvement of insight of illness could be an index of a good therapeutic alliance [108]. In fact, the therapeutic relationship is now indeed considered as the most effective instrument to contrast denial of illness [75,109].

In sum, denial of illness, a shared factor with other severe mental disorders [110], was not found to be a predictor of resistance to treatment but rather to correlate with the phenomenon of treatment resistance.

\section{Motivation to change}

Papers on motivation to change in $\mathrm{AN}$ allowed a better understanding of denial of illness although one main difficulty encountered in this field of research is to understand patients' authentic degree of motivation to recover since there is often a difference between what patients do and say [100].

Studies on motivation to change (33 included in this clinical overview) suggested ways to measure this construct $[17,20,28,30,32,34-52,55-57,60,61]$ and interventions to enhance it $[33,58-60]$. A lower motivation to change was found to correlate with lower BMI [45] and in general a more severe eating and general psychopathology [35,39,54]-full diagnosis, purging behaviors $[33,45,46,56]$, lower compliance to dietary recommendations and slow weight gain $[48,50,57]$, and worse quality of life [51]. These data are in line with Kaye's hypothesis of a vicious cycle of symptoms as maintaining factors in EDs [102].

From the available body of literature emerged a correlation between motivation and psychopathology, even more peculiar in AN than BN [37]. 
In spite of the number of conducted researches, to date it is still controversial whether motivational interventions can be a main road to improve resistance to treatment or not. There is a significant correlation between willingness to recover and good motivation to change [36], but this association is variable and scarcely supported by other studies [32,34,49,60,61]. Moreover, willingness to recover $[52,100,111]$ or the ability to recognize the negative effects of illness [37] can be confused with motivation to change and this misinterpretation could lead not experienced therapists to enhance resistance through its underestimation. In fact, some studies highlight the need to train therapists to notice, understand and value those emotions that usually underpin AN [97,108,112].

The role of neuropsychological aspects - promising and growing research area [113] - is even less studied and the data in literature are contrasting [38,40]: in fact, cognitive rigidity and impaired decision making - stable traits also in recovered individuals - can only partially represent a hindrance to treatments.

Although several lines of evidence exist in support of motivational interventions [58-61], a recent review conducted by Waller [100] questions their effectiveness since the available studies are frequently biased by methodological flaws. In fact, motivational interventions are not stand-alone treatments; therefore, the psychotherapies (i.e. CBT) that they usually support could be responsible for the real effectiveness of these interventions. Hence, motivational interventions - as to date have been described in literature - can only scarcely impact motivation and failed to significantly improve outcomes with the only exception represented by Binge Eating Disorder patients [100]. Other findings did not provide support for the effectiveness of such interventions with long-standing patients [83].

Some hypotheses could be raised to bridge the gap as regards motivation to change: a) too much emphasis has been placed on words instead of facts [100] without considering patients' peculiar strive to please [97] and need for approval [108]; b) motivation has been conceived as a too linear concept whilst patients cannot switch directly from one stage to another; c) the assessment of motivational stages is not adequately considered during treatment planning: often motivational stage and phase of therapy do not match, having resistance to treatments enhanced as a result $[51,58]$; d) motivational models may be too simple and may not to consider patients' ambivalence in an proper manner [70,114,115]; e) an excessive use of verbal persuasion is usually made at the expense of patient autonomy [100,116].

Therefore, only a few studies tried to investigate the process of recovery in $\mathrm{AN}$ and to conceptualize more in detail ambivalence to change and its implications [17].

\section{Ambivalence and meaning of illness}

In this sense, some papers [17,20,43-45,70] highlighted the relevance of both motivation and pervading ambivalence that paralyzing patients while making their decisions. Some authors pointed out the existence of a sort of "anorexic voice", an inner entity disapproving patients and being sometimes overwhelming in respect to their sense of the self $[117,118]$. This voice is even more pervading when the illness gets worse, contributing to hamper treatments. It has been suggested that the link between patients and this $\mathrm{AN}$ voice could play a role in unravelling the issue of ambivalent attitudes towards change, typical of BN individuals too [70]. Thus AN and BN patients would constantly struggle between facing resistance to treatment or valuing it.

From a therapeutic perspective, it could be useful to become familiar with the adaptive function of $\mathrm{AN}$ and its pros and cons, as experienced by the patients $[70,115]$. Therefore, it becomes possible not only to perform a cognitive restructuring, but also to mitigate their distress [24] with two aims: a) to use the empathic approach to understand patients' inner world [89] and to dialogue on both diagnosis [119] and recovery meanings [17]; b) to move the focus of the intervention from pathological beliefs to therapeutic relationship [120].

One way to start addressing resistance to treatment in ED patients is trying to understand the subjective meanings of the illness [75] and patients' environment [121]. We found 5 articles that consider in detail patients' meanings of the disorder and they all agree on considering the "positive" functions of AN as enhancing treatment resistance [20]. In fact, the ED can be a way to feel safe, avoid threatening emotions, communicate with others, and feel strong, special and in control [21].

Considering patients' perspectives for treatments could have several positive implications. First, patients feel themselves as empathically understood [83,108,122,123]; second, it becomes possible to deepen and personalize the comprehension of those feelings that underpin the ED [97] since they can be very different between patients [20]. Third, it is possible to introduce mind and cognitions in therapy - in addition to eating behaviors and body distortions - to avoid resistance and relapses [124]: in fact, if decades ago therapies tended to be excessively focused on family and intra-psychical aspects, now we could incur an opposite risk. Weight restoration should be the starting point of a treatment instead of its main goal. The eating pathology should be considered more as a disturbance of corporeality and as an impairment of embodiment [125] rather than a neurological body image distortion [126]. Fourth, talking about what patients think and feel about the meaning of their illness could provide a therapeutic framework, enabling them to experience their autonomy [120] and supporting an 
empathic relationship. In fact, it is not possible to face the illness without "being with" the patient [16].

However, the attention to the meanings that patients confer to their disorder is a necessary but not sufficient condition to understand the phenomenon of resistance to treatment. In fact, the therapist risks to become emotionally indulgent with iatrogenic and resistanceenhancing results [94]. It is crucial for the therapist to achieve a "firm empathy" [127] because an empathic understanding of the patient is not enough; firm boundaries are of vital importance to counterbalance empathy in the therapeutic relationship. Such elements are not only cognitive but have also a relational meaning and function. Therapists need to address patients' need for boundaries, even if not verbally expressed. The treatment, with its implicit relational instruments [128], enables patients to perceive their therapists as both holding [97,129] and handling $[89,129]$ their self-harming attempts. This could be the result of the struggle for control to achieve a sense of identity that Bruch pointed out decades ago highlighting also that for many AN individuals "the experience of being listened to appeared to be of utmost importance ... instead of having their feelings and the meaning of their communication interpreted" [97]. This balance between the two elements - firmness and empathy - can promote changes in patient's personality and coping through interiorization. Certain pathological behaviors should not be allowed or clearly prohibited. At the same time, it is useful to understand patients' resistances, objections and even their need to feel alone, refused, and poorly understood.

Therapists may also incur the risk to consider only patients' conscious meanings of illness and to underestimate those unconscious, deeper, and even more distressing. In this sense, conscious meaning can over the long-term hide useful elements in treatment and therefore contributing to treatment-resistance [75].

In sum, the clinical effort performed on the meanings of illness - either conscious or not - could help overcome resistance to treatment. The understanding of patients' inner world and attitudes towards the illness can become an operational tool to address the core of treatment-resistance within the therapeutic relationship.

\section{Maintaining factors and treatment outcome}

The complex available models to address resistance to treatment are mainly focused on AN maintaining factors and with this overview we found 22 articles investigating this research area showing interesting and well-organized models $[11,18,39,56,62-79]$. The shared core is the attention to both "symptom treatment" eventually entailing a vicious cycle $[5,18,66-68]$ and negative effects of starvation on brain [130]. Also body image distortions should be addressed in detail $[63,65]$ and body dissatisfaction has been found to correlate with certain styles of attachment [108].
There is robust evidence showing that mental health cannot be reached without recovery of weight, body perception, obsessive thinking on food and body and without regaining a good quality of life.

Moreover, the different models consider personality and interpersonal aspects as premorbid or maintaining factors. Several factors have been called into question as enhancing treatment resistance: 1) low self-esteem and 2) mood intolerance [65]; 3) perfectionism [65,78]; 4) body experiences $[17,125]$; 5) general psychopathology $[39,56,64]$; 6) personality [66-68,72,73,76,79]; 7) interpersonal relationships $[65,75]$; 8) cognitive inflexibility and 9) avoidance of experience and emotions [29,131,132]; 10) care givers' expressed emotion $[14,62,71,75]$; 11) poor problem solving abilities [69];12) scarce social support [64,74]; and 13) reduced relational abilities $[39,69,133]$ (for a review on widely used treatment models see: Hay and colleagues [134]). Evidence on a relationship between dropout, treatment response and both character and temperament $[14,67,135]$ encourages to focus on considering in detail patients' personality.

The extension of research to areas including not only eating symptomatology seems timely and promising: clinicians will probably obtain more instruments to understand their patients, individualize treatments, and handle resistance. However, to date there are no findings supporting such a more articulate approach to AN as regards treatment response. This model can be indeed too detailed for those patients with a less severe psychopathology [136] and RCT are not currently available [109]. Rather- although further studies are needed - an RCT [137] did not show any significant effect in increasing treatment response.

For those patients with an enduring $\mathrm{AN}$ and consolidated maintaining factors, supportive or rehabilitative therapies have been suggested $[58,87,138,139]$ since it is unlikely that certain severe patients will respond to treatments being aware of their resistance. Although these approaches are interesting and potentially useful, to the best of our knowledge there is still no clear consensus in literature on the criteria used to define the chronic course in the ED field [87], making even more problematic to group those patients who would benefit from such supportive treatments.

\section{Therapeutic relationship, countertransference, and management of treatment resistance}

Although further research is needed, the aforementioned studies allowed a better understanding of the AN pathogenesis although they were not effective enough in improving prognosis. Sometimes we cannot see woods for trees and - focusing too much on specific aspects - we could miss the overall emotive exchanges constituting the therapeutic relationship $[24,97]$ and its complex patterns of interaction [53]. 
We retrieved 18 studies investigating the role of the therapeutic relationship on resistance to treatments in AN. It is of interest that these works on one hand refer to decades ago [89], whilst on the other have been only recently conducted [47]. These elements show well the gap in literature that now some authors are trying to fill although both Bruch [97] and Garner [140] underscored the issue of the iatrogenic effect of those therapists who are not able to manage their own emotions. All these papers agree on the importance of emotive aspects within the therapeutic relationship, in treating treatmentresistant AN people. Patients themselves - when describing their recovery process - individuate psychotherapy and relationships as fundamental tools to overcome resistance [88]. In particular, psychotherapy has been described as a continuous and significant experience to achieve selfvalidation [69]. Such opinions match some authors' suggestions highlighting the relevance of sharing treatment plans with patients [41].

In this regard, resistance to treatments should be considered within the therapist-patient interaction [84] involving on one hand patients' and illness features [116] and on the other therapist-related factors [98] and their interaction [90]. In particular, the avoidant [66-68,79,141] and narcissistic [76] personality traits of AN patients, in addition to their disadaptive management of anger [142,143], make the therapeutic alliance difficult, sometimes enhancing the illness and patient's relational isolation.

In fact, EDs - assuming an overarching psychodynamic perspective - are essentially disorders of the development of the self and personality, as Bruch [97] originally conceived and as Skårderud [24] and Stanghellini and Coworkers [125] have recently suggested, placing emphasis also on insecure attachment [108,144] and mentalization impairments [120,145].

In particular, AN patients' deep emotions are characterized by fear, emptiness, anger, and profound demoralization $[116,142,143,146]$. The illness is a desperate and selfharming attempt to control distress, on one hand avoiding emotions and on the other hand expressing them in an exaggerated way or developing an exasperated perfectionism $[95,147]$. In general, emotion avoidance and dysregulation are mostly related to treatment-resistance [95].

Such emotions reverberate in line with therapists' ones, mainly if they are young [98] or lacking supervision [81]. Particularly frustration and anger, but also despair, excessive worry, boredom, and feeling of being manipulated $[81,85,98]$ are common when investigating therapists' countertransference features. Resistance to treatments itself is thought to be the most challenging aspect of the AN treatment, according to studies conducted on clinicians' perspectives [98]. In this regard, treatmentresistance could be linked to a contagious fear of aggressiveness and despair that could involve the therapist too.
Treatments could be influenced by an overemphasis on cognitive [24] or explicit communication factors, whilst the issue could be related to the avoidance of an emotive confrontation on symptomatology and real-life experiences or, more simply, to the lack of an authentic relationship between patient and therapist [16]. An effective therapy to overcome resistance to treatments could be indeed a cognitive-analytic therapy as Dare and Coworkers [148] suggested and tested with RCT.

Psychotherapy - as well as those therapies focused on AN symptomatology - should then help patients to achieve a multi-dimensional understanding of themselves and to manage their feelings and relationships, gradually reshaping the adaptive function of the illness. This psychotherapeutic model was only sporadically tested in literature [68,135] and - although it may look outdated - it could be proposed again in the light of the studies on psychotherapy currently available.

In fact, psychodynamic psychotherapy is currently regaining its role in psychiatry [149], mostly as integrative discipline and science of intimacy useful to achieve a developmental psychopathology and overcoming its traditional concept of science of interpretation [128]. Neurosciences significantly highlighted how relational our mind is [150] and that human beings are wired to be social [151]. Initial findings showed that shared emotions can synchronize brain activity [152]: from a metaanalytic studies of dynamic psychotherapies we now know that they are effective in several mental disorders [153] and that the more they consider affective and emotional aspects the more effective they are [154].

In psychodynamic psychotherapies, two aspects have been considered as key-elements: a) a secure, sensitive, and interactive therapeutic alliance; and $\mathrm{b}$ ) encouraging patients to experience the previously avoided threatening feelings [155]. It is the time to (re)introduce these therapeutic processes in the study of AN treatments. Moreover, the concept of resistance to treatments arose from psychoanalysis, as recently remarked [156], on the basis of Freud's statements [157] clarifying that resistance is intertwined with treatment and that it represents a compromise between the strengths related to recovery and those opposing to it.

AN patients ask their clinicians acceptance, intensity, challenge and mostly competence [53], confronting their knowledge, but even more their relational skills. Being able to provide an empathic understanding is fundamental to train the patients to recognize themselves, and restrain their distress with a good balance of implicit and explicit messages in the here and now of the therapeutic relationship through transference and countertransference [158].

Psychotherapy cannot be manualized enough to avoid the unpredictability of the relationship [128]. To improve the quality of the therapeutic relationship the therapist needs to be authentic, implicit and empathic $[128,159]$. If 
the attunement of the therapeutic relationship turns so profound and intense to become embodied simulation [160], also through mirror neurons [161], therapist and patient can start to share not only the distress but also the ability to limit it. Studies on personality and EDs confirm how often emotional coping can be impaired [162]. Therapist's coping skills can be a useful model to enhance the development of patient's coping. In fact, affected individuals can implicitly feel and consider the change, starting to overcome their resistance and fear, as like as therapists handle their fears of being too frustrating or too sympathetic with their patients [11].

In the therapeutic relationship, AN patients can experience new theories of others' mind [163] and more adaptive forms of reflective self-functioning [164] and through this integration of psychic realities they will be again more aware of their own body [24].

Unfortunately, to date there is still little in the way of addressing the treatment-resistance issue in AN. The studies on the importance of therapeutic relationship in facilitating emotive experiences are still sparse or provide only pilot data $[143,165]$. Although an RCT has been designed in this regard [166], further studies are still warranted to bridge this gap.

\section{Conclusions}

Resistance to treatment and reluctance to recovery represent key-problems in the treatment of individuals affected by AN $[13,17]$. In fact, affected patients often show poor motivation to treatment entailing high levels of dropout $[14,100]$ and negative outcomes with the illness becoming often chronic and eventually mortal [167].

The present work individuated 71 studies that specifically addressed treatment-resistance but - although many factors are possibly involved - a dearth of evidencebased findings in this area emerged.

To date are available more theoretical models rather than evidence-based studies on the most effective way to manage treatment resistance. Future research is warranted to fill these gaps and to pave the way for a better understanding of EDs and their treatments, although a more clear description of resistant patients emerged from the available findings.

As Strober wrote [139], EDs do not randomly affect individuals, but a certain temperament coupled with immature, avoidant and perfectionistic personality traits make people more vulnerable and prone to the ED onset $[162,168]$. Therefore, to earn a resistant patient's trust it is first necessary to recognize the defensive nature of the ED symptoms being also aware of their adaptive function to achieve the mitigation of a profound distress [24]. Hidden by the hyper control of body and food, the main elements are demoralization [141], anger [142,169], low self-esteem, and a great "hunger" of approval and reassurance. AN patients are highly ambivalent about relationships; a disadaptive style of attachment poses the bases for the development of relationships characterized by dependence and fear of others' opinions. Coping abilities are impaired: emotions are ignored and avoided through alexithymia, or are uncontrollable and destructive generating acting-out. In a specular way, the therapist incurs the risk of becoming alexithymic [170], or angry and frustrated [98].

Several aspects need to be considered to avoid these mechanisms: expertize, firmness, awareness of maintaining factors, and mostly a "relational knowledge"; according to Roland Barthes: "no power, a little knowledge, a little wisdom and as much flavor as possible" [171]. There is no possible treatment of symptoms and cognitive distortions without attunement $[128,160]$. Who can motivate the treatment-resistant patient to activate a "voluntary suspension of distrust" [172] to overcome such highly valuable symptoms? Only those therapists who can empathically understand those feeling of uselessness, loneliness, and death that patients often experience and highly value.

Treating resistant patients is a long and winding road entailing inevitable multiple problems in the therapeutic alliance. A secure and firm relationship and the avoidance of premature interpretations and arrogant approaches are both effective elements in fostering a positive therapeutic relationship; it is also fundamental indeed to accept and respect patients' thoughts and wishes [97].

Patients should be provided with a chance to express themselves - even with difficulty - since their most authentic parts are likely to reemerge from the eating obsessions and regain meaning. Only then the psychotherapeutic interventions will not be a priori refused but implemented and sustained by the patients who will be free to regain confidence with their own personality and experiences, also related to food and body. Patients' profound demoralization [107] will be then mitigated with an encouraging relational strategy [173-175] aimed at the development of the self [97].

Is this approach possible in this economic climate and with the current strong need for cost-effective interventions? It could be feasible whether public health policies will be able to consider wider investments also because AN-related costs are considerable and-according to the available data - may be even underestimated [176]. It is well-known that an incorrect treatment of these disorders could entail patients' frustration and increase costs [177]. Other severe and resistant psychiatric disorders could benefit from intensive interventions with economic advantages over the medium-term [178,179]; in fact, costs tend to be higher if a correct psychotherapeutic approach is not provided [180].

The dearth of ED programs may be due to the lack of proper knowledge with sometimes clinicians' attitudes 
and stigma influencing negatively the availability of ED services [98].

In the future it will be indeed necessary a strong effort as regards both public health decisions and clinical training to finally improve ED treatments and prognosis [167], mostly because these disorders affect young individuals and are still largely unclear.

This overview shows some limitations. First, the possible biological factors related to resistance have not been considered. Second, resistance could be addressed also by other articles that are not specifically dedicated to this issue and so we could have omitted some papers. Third, this wide heterogeneity made it particularly challenging to systematically and critically review the papers included in the present work. Therefore, they have been clinically and theoretically discussed. Finally, the need to synthesize such complex and wide topics may have left some aspects not fully covered.

Further studies will have to validate the need for personalized treatments - mostly psychotherapies - [16,181] and for interventions tailored to personality dimensions to attenuate resistance and prevent dropouts. This statement is not in line with some studies $[182,183]$ highlighting that ED treatments - including the specialist supportive clinical management - are all equally effective. But these studies show a relevant selection [184] and randomization bias: patients did not receive a tailored treatment but a default intervention that did not consider patients' peculiar meaning of the disorder. Such research methods can indeed uniform results and potentialities of treatments. The negative emotions that underpin the eating symptomatology [147] should be properly addressed with individualized interventions [148]. A recent RCT [185] demonstrated that focal psychodynamic therapy is an effective treatment for AN. It could represent a promising therapeutic opportunity mostly for those patients who are resistant to treatment since psychodynamic psychotherapy can be highly individualized. Further studies testing the application of this intervention also on resistant patients are needed.

In psychiatry, the therapeutic relationship - crucial also during medication prescription [186] - shows even more importance in psychotherapy [187]: the overcoming of resistance to treatment in AN cannot be possible without a deep patients' understanding, mostly regarding their profound and unique despair, and without sharing with them a long and difficult therapeutic journey [124]. Patients can finally achieve a more mature personality balancing their deficits of the self with strategies to regain confidence in their body and to favorably give up the eating symptomatology.

\section{Abbreviations}

EDs: Eating disorders; AN: Anorexia nervosa; BN: Bulimia nervosa; EDNOS: Eating disorder not otherwise specified; DSM-IV-TR: Diagnostic and statistical manual of mental disorders, fourth edition, text revised; BMI: Body mass index; RCT: Randomized controlled trial; HC: Healthy controls; CBT: Cognitive behavioural therapy.

\section{Competing interests}

The authors have no financial competing interest to disclosure. As regards non-financial competing interests, since SF is a member of the editorial board of the journal, he specifically asked not to be involved in editorial process of this manuscript.

\section{Authors' contributions}

SF conceived this work and supervised the manuscript in all phases of its preparation; GAD wrote both introduction and discussion and critically revised the paper; ND conducted the literature search and wrote part of the result section; FA conducted the literature search and wrote part of the result section; CDB revised extensively the paper. All authors read and approved the final manuscript.

\section{Acknowledgements}

The authors would like to thank Dr. Andrea Ferrero and Dr. Enrica Marzola for their help in manuscript preparation and overview process and Dr. Corine Panepinto and Dr. Matteo Panero for both editing and proofreading.

Received: 5 April 2013 Accepted: 25 October 2013

Published: 7 November 2013

\section{References}

1. Posse PR, Nemeroff CB: The problem of treatment-resistant major psychiatric disorders. In Management of treatment-resistant major psychiatric disorders. Edited by Nemeroff CB. Oxford: Oxford University Press; 2012:3-22.

2. Gabbard GO: Treatment resistance in Personality Disorders. In Management of treatment-resistant major psychiatric disorders. Edited by Nemeroff CB. Oxford: Oxford University Press; 2012:265-284.

3. Klump KL, Bulik CM, Kaye WH, Treasure J, Tyson E: Academy for eating disorders position paper: eating disorders are serious mental illnesses. Int J Eat Disord 2009, 42:97-103.

4. Karwautz AF, Wagner G, Waldherr K, Nader IW, Fernandez-Aranda F, Estivill $X$, Holliday J, Collier DA, Treasure JL: Gene-environment interaction in anorexia nervosa: relevance of non-shared environment and the serotonin transporter gene. Mol Psychiatry 2011, 16:590-592.

5. Kaye W: Eating disorders: hope despite mortal risk. Am J Psychiatry 2009, 166:1309-1311.

6. Keel PK, Brown TA: Update on course and outcome in eating disorders. Int J Eat Disord 2010, 43:195-204.

7. Pohjolainen V, Rasanen P, Roine RP, Sintonen $\mathrm{H}$, Wahlbeck K, Karlsson H: Cost-utility of treatment of bulimia nervosa. Int J Eat Disord 2010, 43:596-602.

8. Abbate Daga G, Facchini F, Delsedime N, De Bacco C, Leone V, Fassino S: Valutazione dei costi nel trattamento ospedaliero dei disturbi del comportamento alimentare. It J Psychopathol 2011, 17:225-245.

9. Haas L, Stargardt T, Schreyoegg J, Schlösser R, Hofmann T, Danzer G, Klapp $\mathrm{BF}$ : Introduction of DRG-based reimbursement in inpatient psychosomatics-an examination of cost homogeneity and cost predictors in the treatment of patients with eating disorders. J Psychosom Res 2012, 73:383-390.

10. Treasure J, Russell G: The case for early intervention in anorexia nervosa: theoretical exploration of maintaining factors. Br J Psychiatry 2011, 199:5-7.

11. Fairburn CG: Evidence-based treatment of anorexia nervosa. Int J Eat Disord 2005, 37(26-30):41-42.

12. Rosenvinge JK, Kuhlefelt Klusmeier A: Treatment for eating disorders from a patient satisfaction perspective: a Norwegian replication of a British study. Eur Eat Disord Rev 2000, 8(4):293-300.

13. Kaplan AS, Garfinkel PE: Difficulties in treating patients with eating disorders: a review of patient and clinician variables. Can J Psychiatry 1999, 44:665-670.

14. Fassino S, Pierò A, Tomba E, Abbate-Daga G: Factors associated with dropout from treatment for eating disorders: a comprehensive literature review. BMC Psychiatry 2009, 9:67

15. Fassino S, Daga GA, Piero A, Rovera GG: Dropout from brief psychotherapy in anorexia nervosa. Psychother Psychosom 2002, 71:200-206. 
16. Fassino S: Psychosomatic approach is the new medicine tailored for patient personality with a focus on ethics, economy, and quality. Panminerva Med 2010, 52:249-264.

17. Nordbø RH, Espeset EM, Gulliksen KS, Skårderud F, Geller J, Holte A: Reluctance to recover in anorexia nervosa. Eur Eat Disord Rev 2012, 20:60-67.

18. Fichter MM, Quadflieg N, Hedlund S: Twelve-year course and outcome predictors of anorexia nervosa. Int J Eat Disord 2006, 39:87-100.

19. Van Son GE, Van Hoeken D, Van Furth EF, Donker GA, Hoek HW: Course and outcome of eating disorders in a primary care-based cohort. Int $J$ Eat Disord 2010, 43:130-138.

20. Nordbø RH, Espeset EM, Gulliksen KS, Skårderud F, Holte A: The meaning of self-starvation: qualitative study of patients' perception of anorexia nervosa. Int J Eat Disord 2006, 39:556-564.

21. Espíndola CR, Blay SL: Anorexia nervosa treatment from the patient perspective: a metasynthesis of qualitative studies. Ann Clin Psychiatry 2009, 21:38-48.

22. Wildes JE, Ringham RM, Marcus MD: Emotion avoidance in patients with anorexia nervosa: initial test of a functional model. Int J Eat Disord 2010, 43:398-404.

23. Wildes JE, Marcus MD: Development of emotion acceptance behavior therapy for anorexia nervosa: a case series. Int J Eat Disord 2011, 44:421-427.

24. Skårderud F: Bruch revisited and revised. Eur Eat Disord Rev 2009, 17:83-88.

25. Couturier JL, Lock J: Denial and minimization in adolescents with anorexia nervosa. Int J Eat Disord 2006, 39:212-216.

26. Gothelf D, Apter A, Ratzoni G, Orbach I, Weizman R, Tyano S, Pfeffer C: Defense mechanisms in severe adolescent anorexia nervosa. J Am Acad Child Adolesc Psychiatry 1995, 34:1648-1654.

27. Konstantakopoulos G, Tchanturia K, Surguladze SA, David AS: Insight in eating disorders: clinical and cognitive correlates. Psychol Med 2011, 41:1951-1961.

28. Konstantakopoulos G, Varsou E, Dikeos D, loannidi N, Gonidakis F, Papadimitriou G, Oulis P: Delusionality of body image beliefs in eating disorders. Psychiatry Res 2012, 200:482-488.

29. Schoen EG, Lee S, Skow C, Greenberg ST, Bell AS, Wiese JE, Martens JK: A retrospective look at the internal help-seeking process in young women with eating disorders. Eat Disord 2012, 20:14-30.

30. Steinglass JE, Eisen JL, Attia E, Mayer L, Walsh BT: Is anorexia nervosa a delusional disorder? An assessment of eating beliefs in anorexia nervosa. J Psychiatr Pract 2007, 13:65-71.

31. Viglione V, Muratori F, Maestro S, Brunori E, Picchi L: Denial of symptoms and psychopathology in adolescent anorexia nervosa. Psychopathology 2006, 39:255-260.

32. Ametller L, Castro J, Serrano E, Martínez E, Toro J: Readiness to recover in adolescent anorexia nervosa: prediction of hospital admission. J Child Psychol Psychiatry 2005, 46:394-400.

33. Ben-Tovim DI, Walker $K$, Gilchrist P, Freeman R, Kalucy R, Esterman A: Outcome in patients with eating disorders: a 5-year study. Lancet 2001, 357:1254-1257.

34. Bewell CV, Carter JC: Readiness to change mediates the impact of eating disorder symptomatology on treatment outcome in anorexia nervosa. Int J Eat Disord 2008, 41:368-371.

35. Burket RC, Hodgin JD: Factors predicting reluctance to seek treatment in patients with eating disorders. South Med J 1993, 86:529-532.

36. Carter JC, Mercer-Lynn KB, Norwood SJ, Bewell-Weiss CV, Crosby RD, Woodside DB, Olmsted MP: A prospective study of predictors of relapse in anorexia nervosa: implications for relapse prevention. Psychiatry Res 2012, 200:518-523.

37. Casasnovas C, Fernández-Aranda F, Granero R, Krug I, Jiménez-Murcia S, Bulik CM, Vallejo-Ruiloba J: Motivation to change in eating disorders: clinical and therapeutic implications. Eur Eat Disord Rev 2007, 15:449-456.

38. Cavedini P, Zorzi C, Bassi T, Gorini A, Baraldi C, Ubbiali A, Bellodi L: Decisionmaking functioning as a predictor of treatment outcome in anorexia nervosa. Psychiatry Res 2006, 145:179-187.

39. Clausen L: Time to remission for eating disorder patients: a 2(1/2)-year followup study of outcome and predictors. Nord J Psychiatry 2008, 62:151-159.

40. Danner UN, Sanders N, Smeets PA, Van Meer F, Adan RA, Hoek HW, Van Elburg AA: Neuropsychological weaknesses in anorexia nervosa: setshifting, central coherence, and decision making in currently ill and recovered women. Int J Eat Disord 2012, 45:685-694.

41. Darcy AM, Katz S, Fitzpatrick KK, Forsberg S, Utzinger L, Lock J: All better? How former anorexia nervosa patients define recovery and engaged in treatment. Eur Eat Disord Rev 2010, 18:260-270.
42. Gale C, Holliday J, Troop NA, Serpell L, Treasure J: The pros and cons of change in individuals with eating disorders: a broader perspective. Int $J$ Eat Disord 2006, 39:394-403.

43. Geller J, Cockell SJ, Drab DL: Assessing readiness for change in the eating disorders: the psychometric properties of the readiness and motivation interview. Psychol Assess 2001, 13:189-198.

44. Geller J, Drab-Hudson DL, Whisenhunt BL, Srikameswaran S: Readiness to change dietary restriction predicts outcomes in the eating disorders. Eat Disord 2004, 12:209-224.

45. Geller J, Cassin SE, Brown KE, Srikameswaran S: Factors associated with improvements in readiness for change: low vs. normal BMl eating disorders. Int J Eat Disord 2009, 42:40-46.

46. Herzog DB, Dorer DJ, Keel PK, Selwyn SE, Ekeblad ER, Flores AT, Greenwood DN, Burwell RA, Keller MB: Recovery and relapse in anorexia and bulimia nervosa: a 7.5-year follow-up study. J Am Acad Child Adolesc Psychiatry 1999, 38:829-837.

47. Karlsson GP, Clinton D, Nevonen L: Prediction of weight increase in anorexia nervosa. Nord J Psychiatry 2013: . Epub ahead of print.

48. Lund BC, Hernandez ER, Yates WR, Mitchell JR, McKee PA, Johnson CL: Rate of inpatient weight restoration predicts outcome in anorexia nervosa. Int J Eat Disord 2009, 42:301-305.

49. McHugh MD: Readiness for change and short-term outcomes of female adolescents in residential treatment for anorexia nervosa. Int J Eat Disord 2007, 40:602-612.

50. Mewes R, Tagay S, Senf W: Weight curves as predictors of short-term outcome in anorexia nervosa inpatients. Eur Eat Disord Rev 2008, 16:37-43.

51. Muñoz P, Quintana JM, Las Hayas C, Padierna A, Aguirre U, González-Torres MA: Quality of life and motivation to change in eating disorders. Perception patient-psychiatrist. Eat Behav 2012, 13:131-134.

52. Nordbø RH, Gulliksen KS, Espeset EM, Skårderud F, Geller J, Holte A: Expanding the concept of motivation to change: the content of patients wish to recover from anorexia nervosa. Int J Eat Disord 2008, 41:635-642.

53. Gulliksen KS, Espeset EM, Nordbø RH, Skårderud F, Geller J, Holte A: Preferred therapist characteristics in treatment of anorexia nervosa: the patient's perspective. Int J Eat Disord 2012, 45:932-941.

54. Ricca V, Castellini G, Lo Sauro C, Mannucci E, Ravaldi C, Rotella F, Faravelli C: Cognitive-behavioral therapy for threshold and subthreshold anorexia nervosa: a three-year follow-up study. Psychother Psychosom 2010, 79:238-248

55. Rieger E, Touyz SW, Beumont PJ: The Anorexia Nervosa Stages of Change Questionnaire (ANSOCQ): information regarding its psychometric properties. Int J Eat Disord 2002, 32:24-38.

56. Salbach-Andrae H, Schneider N, Seifert K, Pfeiffer E, Lenz K, Lehmkuhl U, Korte A: Short-term outcome of anorexia nervosa in adolescents after inpatient treatment: a prospective study. Eur Child Adolesc Psychiatry 2009, 18:701-704

57. Schebendach JE, Mayer LE, Devlin MJ, Attia E, Contento IR, Wolf RL, Walsh $\mathrm{BT}$ : Dietary energy density and diet variety as predictors of outcome in anorexia nervosa. Am J Clin Nutr 2008, 87:810-816.

58. Touyz S, Thornton C, Rieger E, George L, Beumont P: The incorporation of the stage of change model in the day hospital treatment of patients with anorexia nervosa. Eur Child Adolesc Psychiatry 2003, 12(Suppl 1):65-71.

59. Treasure J, Sepulveda AR, Whitaker W, Todd G, Lopez C, Whitney J: Collaborative care between professionals and non-professionals in the management of eating disorders: a description of workshops focussed on interpersonal maintaining factors. Eur Eat Disord Rev 2007, 15:24-34.

60. Wade TD, Frayne A, Edwards SA, Robertson T, Gilchrist P: Motivational change in an inpatient anorexia nervosa population and implications for treatment. Aust N Z J Psychiatry 2009, 43:235-243.

61. Ward A, Troop N, Todd G, Treasure J: To change or not to change-'how' is the question? Br J Med Psychol 1996, 69(Pt 2):139-146

62. Castro J, Toro J, Cruz M: Quality of rearing practices as predictor of shortterm outcome in adolescent anorexia nervosa. Psychol Med 2000, 30:61-67.

63. Danielsen $M, R \varnothing \varnothing$ : Changes in body image during inpatient treatment for eating disorders predict outcome. Eat Disord 2012, 20:261-275.

64. Deter HC, Schellberg D, Köpp W, Friederich HC, Herzog W: Predictability of a favorable outcome in anorexia nervosa. Eur Psychiatry 2005, 20:165-172.

65. Fairburn CG, Cooper Z, Shafran R: Cognitive behaviour therapy for eating disorders: a "transdiagnostic" theory and treatment. Behav Res Ther 2003, 41:509-528 
66. Fassino S, Abbate Daga G, Amianto F, Leombruni P, Fornas B, Garzaro L, D'Ambrosio G, Rovera GG: Outcome predictors in anorectic patients after 6 months of multimodal treatment. Psychother Psychosom 2001, 70:201-208.

67. Fassino S, Abbate Daga G, Amianto F, Leombruni P, Garzaro L, Rovera GG: Nonresponder anorectic patients after 6 months of multimodal treatment: predictors of outcome. Eur Psychiatry 2001, 16:466-473.

68. Fassino S, Abbate Daga G, Delsedime N, Busso F, Piero A, Rovera GG: Baseline personality characteristics of responders to 6-month psychotherapy in eating disorders: preliminary data. Eat Weight Disord 2005, 10:40-50.

69. Federici A, Kaplan AS: The patient's account of relapse and recovery in anorexia nervosa: a qualitative study. Eur Eat Disord Rev 2008, 16:1-10.

70. Geller J: Mechanisms of action in the process of change: helping eating disorder clients make meaningful shifts in their lives. Clin Child Psychol Psychiatry 2006, 11:225-237.

71. Goddard E, Macdonald P, Sepulveda AR, Naumann U, Landau S, Schmidt U, Treasure J: Cognitive interpersonal maintenance model of eating disorders: intervention for carers. Br J Psychiatry 2011, 199:225-231.

72. Helverskov JL, Clausen L, Mors O, Frydenberg M, Thomsen PH, Rokkedal K: Trans-diagnostic outcome of eating disorders: A 30-month follow-up study of 629 patients. Eur Eat Disord Rev 2010, 18:453-463.

73. Hjern A, Lindberg L, Lindblad F: Outcome and prognostic factors for adolescent female in-patients with anorexia nervosa: 9- to 14-year follow-up. Br J Psychiatry 2006, 189:428-432

74. Löwe B, Zipfel S, Buchholz C, Dupont Y, Reas DL, Herzog W: Long-term outcome of anorexia nervosa in a prospective 21-year follow-up study. Psychol Med 2001, 31:881-890.

75. Schmidt U, Treasure J: Anorexia nervosa: valued and visible. A cognitiveinterpersonal maintenance model and its implications for research and practice. Br J Clin Psychol 2006, 45(Pt 3):343-366.

76. Signorini A, Bellini O, Pasanisi F, Contaldo F, De Filippo E: Outcome predictors in the short-term treatment of anorexia nervosa: an integrated medical-psychiatric approach. Eat Weight Disord 2003, 8:168-172.

77. Steinhausen HC, Seidel R, Winkler Metzke C: Evaluation of treatment and intermediate and long-term outcome of adolescent eating disorders. Psychol Med 2000, 30:1089-1098.

78. Sutandar-Pinnock K, Blake Woodside D, Carter JC, Olmsted MP, Kaplan AS: Perfectionism in anorexia nervosa: a 6-24-month follow-up study. Int J Eat Disord 2003, 33:225-229.

79. Vrabel KR, Rø O, Martinsen EW, Hoffart A, Rosenvinge JH: Five-year prospective study of personality disorders in adults with longstanding eating disorders. Int J Eat Disord 2010, 43:22-28.

80. Feld R, Woodside DB, Kaplan AS, Olmsted MP, Carter JC: Pretreatment motivational enhancement therapy for eating disorders: a pilot study. Int J Eat Disord 2001, 29:393-400.

81. Forget $\mathrm{K}$, Marussi DR, Le Corff $\mathrm{Y}$ : Counter-transference in eating disorder treatment:a systematic review. Can J Psychiatry 2011, 56:303-310.

82. Geller J, Brown KE, Srikameswaran S: The efficacy of a brief motivational intervention for individuals with eating disorders: a randomized control trial. Int J Eat Disord 2011, 44:497-505.

83. Masson PC, Sheeshka JD: Clinicians' perspectives on the premature termination of treatment in patients with eating disorders. Eat Disord 2009, 17:109-125.

84. Moyers TB, Rollnick S: A motivational interviewing perspective on resistance in psychotherapy. J Clin Psychol 2002, 58:185-193.

85. Satir DA, Thompson-Brenner H, Boisseau CL, Crisafulli MA: Countertransference reactions to adolescents with eating disorders: relationships to clinician and patient factors. Int J Eat Disord 2009, 42:511-521.

86. Strober M: Managing the chronic, treatment-resistant patient with anorexia nervosa. Int J Eat Disord 2004, 36:245-255.

87. Tierney S, Fox JR: Chronic anorexia nervosa: a Delphi study to explore practitioners' views. Int J Eat Disord 2009, 42:62-67.

88. Tozzi F, Sullivan PF, Fear JL, McKenzie J, Bulik CM: Causes and recovery in anorexia nervosa: the patient's perspective. Int J Eat Disord 2003, 33:143-154.

89. Vitousek K, Watson S, Wilson GT: Enhancing motivation for change in treatment-resistant eating disorders. Clin Psychol Rev 1998, 18:391-420.

90. Warren CS, Crowley ME, Olivardia R, Schoen A: Treating patients with eating disorders: an examination of treatment providers' experiences. Eat Disord 2009, 17:27-45.

91. American Psychiatric Association: Diagnostic and statistical manual of mental disorders. 4th edition. Washington DC: Masson; 2000.
92. Prochaska JO, Redding CA, Evers KE: The transtheoretical model and stages of change. In Health behavior and health education: Theory, research, and practice. Edited by Glanz K, Rimer BK, Viswanath K. San Francisco: Jossey-Bass; 2002:60-84.

93. Treasure J, Schmidt U: MI in the management of eating disorders. In Motivational Interviewing in the Treatment of Psychological Problems. Edited by Arkowitz H, Westra HA, Miller WR, Rollnick S. New York: The Guilford Press; 2010.

94. Treasure J, Crane A, McKnight R, Buchanan E, Wolfe M: First do no harm: iatrogenic maintaining factors in anorexia nervosa. Eur Eat Disord Rev 2011, 19:296-302.

95. Thompson-Brenner H, Eddy KT, Franko DL, Dorer DJ, Vashchenko M, Kass AE, Herzog DB: A personality classification system for eating disorders: a longitudinal study. Compr Psychiatry 2008, 49:551-560.

96. Russell GF: Metabolic, endocrine and psychiatric aspects of anorexia nervosa. Sci Basis Med Annu Rev 1969:236-255

97. Bruch H: Anorexia Nervosa: therapy and theory. Am J Psychiatry 1982 139:1531-1538.

98. Thompson-Brenner H, Satir DA, Franko DL, Herzog DB: Clinician reactions to patients with eating disorders: a review of the literature. Psychiatr Serv 2012, 63:73-78.

99. Marzola E, Trunko ME, Grenesko-Stevens E, Kaye WH: Anorexia and Bulimia Nervosa. In Management of treatment-resistant major psychiatric disorders. Edited by Nemeroff CB. Oxford: Oxford University Press; 2012:197-224

100. Waller G: The myths of motivation: time for a fresh look at some received wisdom in the eating disorders? Int J Eat Disord 2012, 45:1-16.

101. Fassino S, Daga GA, Pierò A, Delsedime N: Psychological factors affecting eating disorders. Adv Psychosom Med 2007, 28:141-168.

102. Kaye $W H$, Fudge $J$, Paulus M: New insights into symptoms and neurocircuit function of anorexia nervosa. Nat Rev Neurosci 2009, 10:573-584.

103. Wamberg E, Marcus ER: Processo, resistenza, interpretazione. In Psicoanalisi. Teoria, clinica, ricerca. Edited by Person ES, Cooper AM, Gabbard GO. Milano: Raffaello Cortina Editore; 2004:373-393.

104. Nemeroff CB: Management of treatment-resistant major psychiatric disorders. Oxford: Oxford University Press; 2012.

105. Fabbri S, Fava GA, Sirri L, Wise TN: Development of a new assessment strategy in psychosomatic medicine: the diagnostic criteria for psychosomatic research. Adv Psychosom Med 2007, 28:1-20.

106. Guarda AS: Treatment of anorexia nervosa: insights and obstacles. Physiol Behav 2008, 94:113-120.

107. Abbate-Daga G, Delsedime N, Nicotra B, Giovannone C, Marzola E, Amianto $F$, Fassino S: Psychosomatic syndromes and anorexia nervosa. BMC Psychiatry 2013, 13:14.

108. Abbate-Daga G, Gramaglia C, Amianto F, Marzola E, Fassino S: Attachment insecurity, personality, and body dissatisfaction in eating disorders. J Nerv Ment Dis 2010, 198:520-524.

109. Fairburn CG, Cooper Z, Doll HA, O'Connor ME, Palmer RL, Dalle Grave R: Enhanced cognitive behaviour therapy for adults with anorexia nervosa: a UK-Italy study. Behav Res Ther 2013, 51:R2-R8.

110. Wiffen BD, O'Connor JA, Gayer-Anderson C, Reis Marques T, McQueen G, Happé F, Murray RM, David AS: "I am sane but he is mad": Insight and illness attributions to self and others in psychosis. Psychiatry Res 2013: Epub ahead of print.

111. Malson H, Bailey L, Clarke S, Treasure J, Anderson G, Kohn M: Un/ imaginable future selves: a discourse analysis of in-patients' talk about recovery from an "eating disorder". Eur Eat Disord Rev 2011, 19:25-36.

112. Adenzato M, Todisco P, Ardito RB: Social cognition in anorexia nervosa: evidence of preserved theory of mind and impaired emotional functioning. PLoS One 2012, 7:e44414.

113. Abbate-Daga G, Buzzichelli S, Marzola E, Amianto F, Fassino S: Effectiveness of cognitive remediation therapy (CRT) in anorexia nervosa: a case series. J Clin Exp Neuropsychol 2012, 34:1009-1015.

114. Serpell L, Treasure J: Bulimia nervosa: friend or foe? The pros and cons of bulimia nervosa. Int J Eat Disord 2002, 32:164-170.

115. Serpell $L$, Teasdale JD, Troop NA, Treasure J: The development of the PCAN, a measure to operationalize the pros and cons of anorexia nervosa. Int J Eat Disord 2004, 36:416-433.

116. Treasure J, Schmidt U: Anorexia Nerv. Clin Evid 2004, 11:1192-1203.

117. Tierney S, Fox JR: Living with the anorexic voice: a thematic analysis. Psychol Psychother 2010, 83:243-254. 
118. Williams S, Reid M: "It"s like there are two people in my head': a phenomenological exploration of anorexia nervosa and its relationship to the self. Psychol Health 2012, 27:798-815.

119. Barron JW: Making diagnosis meaningful: Enhancing evaluation and treatment of psychological disorders. Washington DC: American Psychological Association; 1998.

120. Skårderud F: Eating one's words, part I: "Concretised metaphors" and reflective function in anorexia nervosa-an interview study. Eur Eat Disord Rev 2007, 15:163-174.

121. Fassino S, Amianto F, Rocca G, Daga GA: Original articles parental bonding and eating psychopathology in bulimia nervosa: personality traits as possible mediators. Epidemiol Psichiatr Soc 2010, 19(3):214-222.

122. Mahon J, Winston AP, Palmer RL, Harvey PK: Do broken relationships in childhood relate to bulimic women breaking off psychotherapy in adulthood? Int J Eat Disord 2001, 29:139-149.

123. Money C, Genders R, Treasure J, Schmidt U, Tchanturia K: A brief emotion focused intervention for inpatients with anorexia nervosa: a qualitative study. J Health Psychol 2011, 16:947-958.

124. Jenkins J, Ogden J: Becoming "whole" again: a qualitative study of women's views of recovering from anorexia nervosa. Eur Eat Disord Rev 2012, 20:e23-e31.

125. Stanghellini G, Castellini G, Brogna P, Faravelli C, Ricca V: Identity and eating disorders (IDEA): a questionnaire evaluating identity and embodiment in eating disorder patients. Psychopathology 2012, 45:147-158

126. Hasan TF, Hasan H: Anorexia nervosa: a unified neurological perspective. Int J Med Sci 2011, 8:679-703.

127. Wilson GT, Fairburn CG, Agras WS: Cognitive behavioral therapy for bulimia nervosa. In Handbook of Treatment for Eating Disorders. Edited by Garner DM, Garfinkel PE. New York: The Guilford Press; 1997:67-93.

128. Bruschweiler-Stern N, Lyons-Ruth K, Morgan AC, Nahum JP, Sander LW, Stern DN: The foundational level of psychodynamic meaning: implicit process in relation to conflict, defense and the dynamic unconscious. Int J Psychoanal 2007, 88(Pt 4):843-860.

129. Winnicott DW: The development of the capacity for concern. Bull Menninger Clin 1963, 27:167-176.

130. Freeman MP: Nutrition and psychiatry. Am J Psychiatry 2010, 167:244-247.

131. Oldershaw A, Hambrook D, Stahl D, Tchanturia K, Treasure J, Schmidt U: The socio-emotional processing stream in Anorexia Nervosa. Neurosci Biobehav Rev 2011, 35:970-988.

132. Abbate-Daga G, Buzzichelli S, Amianto F, Rocca G, Marzola E, McClintock SM, Fassino S: Cognitive flexibility in verbal and nonverbal domains and decision making in anorexia nervosa patients: a pilot study. BMC Psychiatry 2011, 11:162

133. Krug I, Penelo E, Fernandez-Aranda F, Anderluh M, Bellodi L, Cellini E, Di Bernardo M, Granero R, Karwautz A, Nacmias B, Ricca V, Sorbi S, Tchanturia K, Wagner G, Collier D, Treasure J: Low social interactions in eating disorder patients in childhood and adulthood: a multi-centre European case control study. J Health Psychol 2013, 18:26-37.

134. Hay PJ, Touyz S, Sud R: Treatment for severe and enduring anorexia nervosa: a review. Aust N Z J Psychiatry 2012, 46:1136-1144.

135. Fassino S, Abbate-Daga G, Amianto F, Facchini F, Rovera GG: Eating psychopathology and personality in eating disorders. Epidemiol Psichiatr SoC 2003, 12:293-300.

136. Fairburn CG, Cooper Z, Doll HA, O'Connor ME, Bohn K, Hawker DM, Wales JA, Palmer RL: Transdiagnostic cognitive-behavioral therapy for patients with eating disorders: a two-site trial with 60-week follow-up. Am J Psychiatry 2009, 166:311-319.

137. Schmidt U, Oldershaw A, Jichi F, Sternheim L, Startup H, McIntosh V, Jordan J, Tchanturia K, Wolff G, Rooney M, Landau S, Treasure J: Out-patient psychological therapies for adults with anorexia nervosa: randomised controlled trial. Br J Psychiatry 2012, 201:392-399.

138. McIntosh W, Jordan J, Luty SE, Carter FA, McKenzie JM, Bulik CM, Joyce PR: Specialist supportive clinical management for anorexia nervosa. Int J Eat Disord 2006, 39:625-632.

139. Strober M: The Chronically III Patient with Anorexia Nervosa. Development, Phenomenology, and Therapeutic Considerations. In The treatment of eating disorders: a clinical handbook. Edited by Grilo C, Mitchell JE. New York: Guilford Press; 2010:225-233.

140. Garner DM, Garfinkel PE: Perceptive and cognitive disturbances. In Anorexia nervosa: a multidimensional perspective. Edited by Garfinkel PE, Garner DM. New York: Brunner \& Mazel; 1982:123-163.
141. Abbate Daga G, Gramaglia C, Bailer U, Bergese S, Marzola E, Fassino S: Major depression and avoidant personality traits in eating disorders. Psychother Psychosom 2011, 80:319-320

142. Fassino S, Daga GA, Pierò A, Leombruni P, Rovera GG: Anger and personality in eating disorders. J Psychosom Res 2001, 51:757-764.

143. Abbate-Daga G, Marzola E, Gramaglia C, Brustolin A, Campisi S, De-Bacco C, Amianto F, Fassino S: Emotions in eating disorders: changes of anger control after an emotion-focused day hospital treatment. Eur Eat Disord Rev 2012, 20:496-501.

144. Zachrisson HD, Skårderud F: Feelings of insecurity: review of attachment and eating disorders. Eur Eat Disord Rev 2010, 18:97-106.

145. Rothschild-Yakar L, Levy-Shiff R, Fridman-Balaban R, Gur E, Stein D: Mentalization and relationships with parents as predictors of eating disordered behavior. J Nerv Ment Dis 2010, 198:501-507.

146. Truglia E, Mannucci E, Lassi S, Rotella CM, Faravelli C, Ricca V: Aggressiveness, anger and eating disorders: a review. Psychopathology 2006, 39:55-68.

147. Wildes JE, Marcus MD, Bright AC, Dapelo MM, Psychol MC: Emotion and eating disorder symptoms in patients with anorexia nervosa: An experimental study. Int J Eat Disord 2012, 45:876-882.

148. Dare C, Eisler I, Russell G, Treasure J, Dodge L: Psychological therapies for adults with anorexia nervosa: randomised controlled trial of out-patient treatments. Br J Psychiatry 2001, 178:216-221.

149. Holmes J: Psychodynamic psychiatry's green shoots. Br J Psychiatry 2012, 200:439-441.

150. Siegel DJ: The Developing Mind. New York: The Guilford Press Inc. and Mark Paterson; 1999

151. Castiello U, Becchio C, Zoia S, Nelini C, Sartori L, Blason L, D'Ottavio G, Bulgheroni M, Gallese V: Wired to be social: the ontogeny of human interaction. PLoS One 2010, 5:e13199.

152. Nummenmaa L, Glerean $E$, Viinikainen $M$, Jääskeläinen IP, Hari R, Sams M: Emotions promote social interaction by synchronizing brain activity across individuals. Proc Natl Acad Sci U S A 2012, 109:9599-9604

153. Leichsenring F, Rabung S: Effectiveness of long-term psychodynamic psychotherapy: a meta-analysis. JAMA 2008, 300:1551-1565.

154. Diener MJ, Hilsenroth MJ, Weinberger J: Therapist affect focus and patient outcomes in psychodynamic psychotherapy: a meta-analysis. Am J Psychiatry 2007, 164:936-941.

155. Shedler J: The efficacy of psychodynamic psychotherapy. Am Psychol 2010, 65:98-109.

156. Person ES, Cooper AM, Gabbard GO: Psicoanalisi. Teoria, clinica, ricerca. Raffaello Cortina Editore: Milano; 2005.

157. Freud S: The Dynamics of Transference. In The Standard Edition of the Complete Psychological Works of Sigmund Freud, Volume XII (1911-1913): The Case of Schreber, Papers on Technique and Other Works. London: Hogarth Press; 1912:97-108.

158. Fosshage $\mathrm{J}$ : The explicit and implicit dance in psychoanalytic change. J Anal Psychol 2004, 49:49-65

159. Stern DN, Sander LW, Nahum JP, Harrison AM, Lyons-Ruth K, Morgan AC Bruschweiler-Stern N, Tronick EZ: Non-interpretive mechanisms in psychoanalytic therapy. The "something more" than interpretation. The process of change study group. Int J Psychoanal 1998, 79(5):903-921.

160. Gallese V: Before and below "theory of mind": embodied simulation and the neural correlates of social cognition. Philos Trans R Soc Lond B Biol SCi 2007, 362:659-669.

161. Fan Y, Duncan NW, De Greck M, Northoff G: Is there a core neural network in empathy? An fMRI based quantitative meta-analysis. Neurosci Biobehav Rev 2011, 35:903-911.

162. Fassino S, Amianto F, Gramaglia C, Facchini F, Abbate Daga G: Temperament and character in eating disorders: ten years of studies. Eat Weight Disord 2004, 9:81-90.

163. Tchanturia K, Anderluh MB, Morris RG, Rabe-Hesketh S, Collier DA, Sanchez $P$, Treasure $J$ : Cognitive flexibility in anorexia nervosa and bulimia nervosa. J Int Neuropsychol Soc 2004, 10:513-520.

164. Ward A, Ramsay R, Turnbull S, Steele M, Steele H, Treasure J: Attachment in anorexia nervosa: a transgenerational perspective. Br J Med Psychol 2001, 74:497-505

165. Gramaglia C, Abbate Daga G, Amianto F, Brustolin A, Campisi S, De Bacco C, Fassino S: Cinematherapy in the day hospital treatment of patients with eating disorders. Case study and clinical considerations. Arts Psychother 2011, 38:261-266 
166. Wild B, Friederich HC, Gross G, Teufel M, Herzog W, Giel KE, De Zwaan M, Schauenburg H, Schade-Brittinger C, Schäfer H, Zipfel S: The ANTOP study: focal psychodynamic psychotherapy, cognitive-behavioural therapy, and treatment-as-usual in outpatients with anorexia nervosa-a randomized controlled trial. Trials 2009, 10:23.

167. Steinhausen HC: The outcome of anorexia nervosa in the 20th century. Am J Psychiatry 2002, 159:1284-1293.

168. Fassino S, Abbate-Daga G, Amianto F, Leombruni P, Boggio S, Rovera GG: Temperament and character profile of eating disorders: a controlled study with the temperament and character inventory. Int J Eat Disord 2002, 32:412-425.

169. Amianto F, Abbate-Daga G, Morando S, Sobrero C, Fassino S: Personality development characteristics of women with anorexia nervosa, their healthy siblings and healthy controls: What prevents and what relates to psychopathology? Psychiatry Res 2011, 187:401-408.

170. Shapiro J: Perspective: does medical education promote professional alexithymia? a call for attending to the emotions of patients and self in medical training. Acad Med 2011, 86:326-332.

171. Barthes R: Leçon. Paris: Éd. du Seuil; 1979.

172. Kohut H: The Restoration of the Self. New York: International Universities Press; 1977.

173. Watts RE, Pietrzak D: Adlerian "encouragement" and the therapeutic process of solution-focused brief therapy. J Couns Dev 2000, 78(4):442-447.

174. Rovera GG: Le strategie dell'incoraggiamento. Riv Psicol Indiv 2009, 66:139-169.

175. Fassino S, Amianto F, Ferrero A: Brief Adlerian psychodynamic psychotherapy: theoretical issues and process indicators. Panminerva Med 2008, 50:165-175.

176. Stuhldreher N, Konnopka A, Wild B, Herzog W, Zipfel S, Löwe B, König H-H: Cost-of-illness studies and cost-effectiveness analyses in eating disorders: a systematic review. Int J Eat Disord 2012, 45:476-491.

177. Vandereycken $\mathrm{W}$ : The place of inpatient care in the treatment of anorexia nervosa: questions to be answered. Int J Eat Disord 2003, 34:409-422.

178. Bateman AW, Fonagy P: Treatment of borderline personality disorder with psychoanalytically oriented partial hospitalization: an 18-month follow-up. Am J Psychiatry 2001, 158:36-42.

179. Bateman AW, Fonagy P: The development of an attachment-based treatment program for borderline personality disorder. Bull Menninger Clin 2003, 67:187-211.

180. Lazar SG: Psychotherapy Is Worth It. A Comprehensive Review of Its Costeffectiveness. Washington DC: American Psychiatric Publishing; 2010.

181. Fassino S, Amianto F, Sobrero C, Abbate Daga G: Does it exist a personality core of mental illness?A systematic review on core psychobiological personality traits in mental disorders. Panminerva Med: in press.

182. McIntosh W, Jordan J, Carter FA, Luty SE, McKenzie JM, Bulik CM, Frampton CM, Joyce PR: Three psychotherapies for anorexia nervosa: a randomized, controlled trial. Am J Psychiatry 2005, 162:741-747.

183. Carter FA, Jordan J, McIntosh W, Luty SE, McKenzie JM, Frampton CM, Bulik CM, Joyce PR: The long-term efficacy of three psychotherapies for anorexia nervosa: a randomized, controlled trial. Int J Eat Disord 2011, 44:647-654.

184. Halmi KA, Agras WS, Crow S, Mitchell J, Wilson GT, Bryson SW, Kraemer $\mathrm{HC}$ : Predictors of treatment acceptance and completion in anorexia nervosa: implications for future study designs. Arch Gen Psychiatry 2005, 62:776-781.

185. Zipfel S, Wild B, Groß G, Friederich HC, Teufel M, Schellberg D, Giel KE, de Zwaan M, Dinkel A, Herpertz S, Burgmer M, Löwe B, Tagay S, von Wietersheim J, Zeeck A, Schade-Brittinger C, Schauenburg H, Herzog W, on behalf of the ANTOP study group: Focal psychodynamic therapy, cognitive behaviour therapy, and optimised treatment as usual in outpatients with anorexia nervosa (ANTOP study): randomised controlled trial. Lancet 2013: [Epub ahead of print].
186. McKay KM, Imel ZE, Wampold BE: Psychiatrist effects in the psychopharmacological treatment of depression. J Affect Disord 2006, 92:287-290

187. Heinonen $E$, Lindfors $O$, Laaksonen MA, Knekt $P$ : Therapists' professional and personal characteristics as predictors of outcome in short- and longterm psychotherapy. J Affect Disord 2012, 138:301-312.

doi:10.1186/1471-244X-13-294

Cite this article as: Abbate-Daga et al:: Resistance to treatment and change in anorexia nervosa: a clinical overview. BMC Psychiatry 2013 13:294

\section{Submit your next manuscript to BioMed Central and take full advantage of:}

- Convenient online submission

- Thorough peer review

- No space constraints or color figure charges

- Immediate publication on acceptance

- Inclusion in PubMed, CAS, Scopus and Google Scholar

- Research which is freely available for redistribution

Submit your manuscript at www.biomedcentral.com/submit
C) Biomed Central 